\section{Dentistry representative body appoints new chair}

The Association of Dental Groups (ADG), which represents group and corporate providers of NHS and private dentistry, has appointed former Conservative MP Neil Carmichael as its new chair with effect from 1 February 2019.

Carmichael takes over the post from David Worskett, the ADG's founding chair, who is retiring after seven years in the role.

Conservative MP for Stroud until the 2017 General Election, Carmichael was chair of the Education Select Committee. Before that, he took an interest in healthcare including establishing an all-party Parliamentary group on health issues and he is currently, inter alia, an Honorary Professor of Politics and Education at Nottingham University and an adviser to a public affairs consultancy.

Carmichael said: 'I am delighted to have been appointed Chair of the ADG. I am looking forward to building on David's achievements over the last seven years - I know members are hugely grateful to him for all he has done.

'As public health and, in particular, dentistry respond to increasing demands on provision, ongoing reform within the NHS and workforce planning issues, I am ready to help ensure the interests of the ADG are strongly advanced as public policy is formulated and reforms are introduced. Dentistry must be at the top of the agenda.'

Worskett said: 'The ADG is absolutely delighted that Neil is taking over the role of independent Chair of the Association. He is highly regarded across the political boundaries and was an outstanding Chair of the House of Commons Select Committee on Education.

'However, Neil also has long-standing experience of the wider healthcare sector and that, together with his political and parliamentary background, will be invaluable in ensuring that dentistry gets more of the focus it deserves and needs in the future.'

\title{
New drive to tackle tooth decay in under-fives
}

Health professionals are launching a $£ 1.5$ million programme that will use collaborative working between different professions to tackle poor oral health amongst under-fiveyear-olds across Greater Manchester.

The programme, organised by the Greater Manchester Health and Social Care Partnership, could benefit thousands of young children in the region where having a tooth removed is the most common reason for young children to be admitted to hospital.

Under the scheme, supervised toothbrushing will be introduced in schools and nurseries, and dental care will be incorporated into health visitor checks in areas where particularly large numbers of young children have tooth decay.

More than a third of five year olds across Greater Manchester experience tooth decay, which is higher than the England national average of $25 \%$. In some local areas in the region, the number of young children affected reaches more than half.

This has resulted, said the Partnership, in more than 15,000 tooth extractions being carried out on local children in the past four years $-60 \%$ more than the national rate for England.

The Partnership is targeting four areas in Greater Manchester with the programme - Salford, Rochdale, Bolton and Oldham - because they were identified by the NHS and Public Health England (PHE) as being among the country's top national priority areas for improving children's oral health.

Currently around half of all five-year-olds in Salford and Oldham (51\%) start school with tooth decay and levels of decay in Rochdale and Bolton are $44 \%$ and $41 \%$, respectively.

Working with local schools and nurseries in each area, the new Partnership programme aims to reach $90 \%$ of under-fives in each area through activities including:

- Introducing daily supervised toothbrushing in schools and nurseries for children aged two to five years

- Training a network of dedicated 'dental champions', supported by expert external staff, to lead the way in improving dental care in early years settings

- Distributing toothbrush/toothpaste packs through health visitor checks

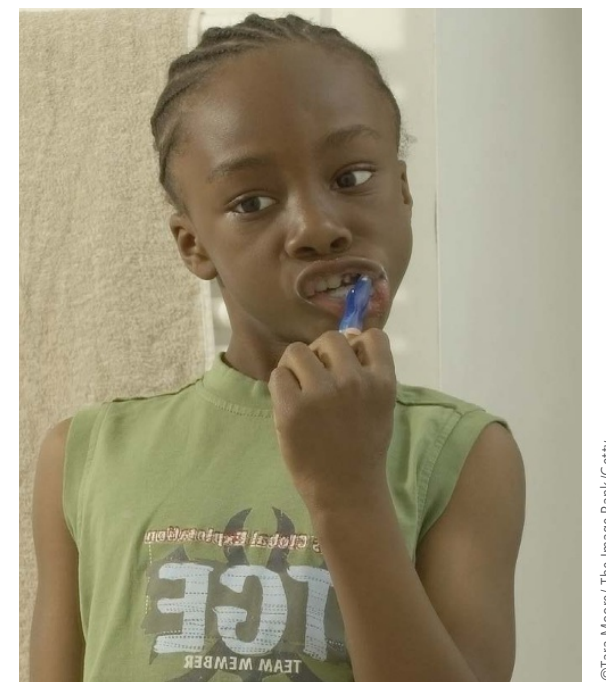

- Encouraging families to make dental visits in the first year of each child's life

- Improving access to quality dental services for those aged under five.

Each of these activities is designed to tackle the widespread impact of high sugar diets and make regular toothbrushing the norm.

The programme coincides with a recently launched PHE campaign ${ }^{1}$ to support families to cut back on sugar by encouraging parents and carers to swap some foods to reduce children's sugar intake and give them healthier versions of the foods and drinks they eat.

Claire Stevens, paediatric dentistry consultant at Manchester University NHS Foundation Trust and children's oral health lead with the Partnership said: 'This new initiative is aiming to tackle the very real problems we face in Greater Manchester with large numbers of young children experiencing significant tooth decay often before they even reach school age.

'Such problems can cause pain, sleepless nights and missed days of school for many children. Across Greater Manchester, this is adding to the daily challenges faced by many of our least well-off families and putting additional pressures on the NHS. Our new $£ 1.5$ million oral health programme will tackle these impacts and will hopefully play a vital role in our ambition of giving all of our children the best start in life.'

1. Public Health England. Sugar Swaps for Kids. Available at https://www.nhs.uk/change4life/food-facts/sugar/sugarswaps-for-kids. (accessed January 2019). 